\title{
Rancang Bangun Animasi Interaktif Berbasis Multimedia Pada Pengenalan Dasar Bahasa Jepang
}

\author{
Safitri Linawati ${ }^{1}$, Siti Nurajizah ${ }^{2}$ \\ ${ }^{1}$ Program Studi Sistem Informasi, Universitas Nusa Mandiri \\ Jl. Raya Jatiwaringin, Cipinang Melayu, Makasar, Jakarta Timut-13630, Indonesia \\ ${ }^{2}$ Program Studi Sistem Informasi Akuntansi, Universitas Bina Sarana Informatika \\ Jl. Kramat Raya No.98, Jakarta Pusat, DKI Jakarta 10450, Indonesia \\ e-mail: ${ }^{1}$ Safitri.swt@ @usamandiri.ac.id, ${ }^{2}$ Siti.snz@bsi.ac.id
}

Artikel Info : Diterima : 10-06-2021 | Direvisi : 29-06-2021 | Disetujui : 05-07-2021

\begin{abstract}
Abstrak - Penggunaan bahasa sebagai media komunikasi saat ini menjadi hal yang penting. Bahasa merupakan cara untuk berkomunikasi dan berinteraksi dengan orang lain. Selain bahasa inggris yang menjadi bahasa internasional, terdapat beberapa bahasa negara lain yang juga tidak kalah diminati untuk dipelajari, salah satunya adalah bahasa jepang. Bahasa jepang memiliki struktur penulisan serta pengucapan yang unik, sehingga dibutuhkan ketekunan dalam mempelajarinya. Namun penggunaan huruf, susunan kalimat, serta struktur tata bahasa yang berbeda dengan tata bahasa indonesia menjadikan para pemula sulit untuk mempelajari bahasa jepang. Penulis mencoba untuk membuat sebuah aplikasi yang menghubungkan antara fungsi multimedia yang ada dalam komputer dengan pengetahuan tentang pengenalan dasar bahasa Jepang. Dalam penelitian ini menggunakan metode pengembangan perangkat lunak waterfall dalam pembuatan animasi pengenalan dasar bahasa jepang. Hasil dari penelitian ini adalah sebuah animasi yang membahas tentang pengenalan negara Jepang, huruf yang digunakan dalam bahasa Jepang, ungkapan salam yang sering digunakan dalam kehidupan sehari-hari, serta cara memperkenalkan diri dalam bahasa Jepang yang disajikan dalam bentuk animasi interaktif sehingga dapat membantu para pengguna untuk memahami dasar bahasa Jepang.
\end{abstract}

Kata kunci: animasi; bahasa jepang; multimedia.

Abstracts - The use of language as a medium of communication is currently important. Language is a way to communicate and interact with other people. Selain bahasa inggris yang menjadi bahasa internasional, terdapat beberapa bahasa negara lain yang juga tidak kalah diminati untuk dipelajari, salah satunya adalah bahasa jepang. Japanese language has a unique writing and pronunciation structure, so it takes persistence in learning it. However, the use of letters, sentence structure, and grammar structures that are different from Indonesian grammar makes it difficult for beginners to learn Japanese. The author tries to create an application that connects the multimedia functions on the computer with the knowledge of basic Japanese language introduction. In this study, using the waterfall software development method in making animation of basic Japanese language introduction. The result of this research is an animation that discusses the introduction of the country of Japan, the letters used in Japanese, greetings that are often used in everyday life, and how to introduce oneself in Japanese which is presented in the form of interactive animation so that it can help users. to understand basic Japanese.

Keywords: animation; japanese; multimedia.

\section{PENDAHULUAN}

Kegiatan berkomunikasi adalah bagian yang hakiki dalam kehidupan bermasyarakat (Sitepu \& Rita, 2017). Bahasa juga merupakan salah satu cara menegetahui respon dari interaksi antar manusia (Komarudin \& Noor, 2017). Tetapi, banyak diantara individu pada umumnya hanya menguasai bahasa daerah asal mereka saja serta tentunya bahasa negara sendiri. Era digitalisasi saat ini menuntut seseorang untuk memenuhi kebutuhan terhadap pengembangan diri dalam penguasaan bahasa asing yang merupakan salah satu faktor dalam leadership 
identity (Akhbar et al., 2018). Hal ini tentu sangat diperlukan dalam mendukung aktulisasi diri terhadap kemampuan penguasaan bahasa internasional dalam hal ini tentu saja bahasa asing. Di setiap lini aktifitas masyarakat tidak terlepas dari sarana teknologi informasi seperti internet, website, gadget dan teknologi lainnya (Arnada \& Putra, 2018). Hal ini dikarenakan era globalisasi yang terus berkembang dengan pesat.

Komunikasi melalui bahasa memungkinkan tiap orang untuk menyesuaikan dirinya dengan lingkungan fisik dan lingkungan sosialnya serta memungkinkan tiap orang untuk mempelajari kebiasaan, adat istiadat, kebudayaan serta latar belakangnya masing-masing.

Huruf-huruf yang digunakan dalam bahasa jepang antara lain(Rostineu, 2018) :

Huruf hiragana adalah huruf asli jepang yang digunakan dalam setiap kata atau kalimat dalam bahasa jepang. Kemudian Huruf katakana adalah huruf yang dipakai untuk menulis kata-kata yang berasal dari bahasa asing atau serapan, nama orang asing, dan tempat asing. Dan yang terakhir Huruf kanji adalah huruf yang berasal dari Cina dan sering digunakan dalam bahasa Jepang. Huruf kanji ini merupakan simbol untuk mewakili sebuah benda. Dalam penggunaanya, huruf kanji bisa berdiri sendiri ataupun disandingkan dengan huruf kanji lain.

Dalam perihal penyampaian makna, kata-kata dalam aplikasi multimedia dapat menjadi faktor yang bisa dipergunakan guna memperluas cakupan teks pada saat proses pengecekan suatu topik tertentu. Multimedia menjadikan sebuah pesan dapat tersampaikan dengan mudah karena didukung dengan bunyi, gambar, video yang lebih menarik dilihat (Anwar et al., 2018).

Bahasa inggris masih menjadi bahasa utama dalam standar kategori bahasa internasional (Fatihaturosyidah \& Septiana, 2019). Beberapa bahasa dari negara lain juga banyak diminati untuk dipelajari, salah satunya adalah bahasa jepang. Bahasa jepang terdapat beberapa perbandingan dalam penggunaan huruf, susunan kalimat, serta struktur tata bahasa yang berbeda dengan bahasa indonesia. Hal ini membuat para pemula terkendala untuk mempelajari bahasa jepang (Asih et al., 2018). Bahasa Jepang adalah pengetahuan yang harus diterapkan di kehidupan sehari-hari, semakin sering berlatih dan praktik maka peserta didik akan menguasainya dengan cepat, dengan adanya multimedia pembelajaran maka pembelajaran akan lebih efektif (Gunawan et al., 2020).

Animasi interaktif merupakan salah satu media pembelajaran yang menggunakan media audio visual sebagai media penyampaiannya (Rosmiati, 2019). Animasi dapat diartikan sebagai proses perubahan visual yang terjadi sepanjang waktu dengan memberikan kekuatan proyek multimedia dan halaman web yang dibuat.Teknik animasi ini mempunyai banyak frame yang berjalan secara berurutan. Anime memakai tokoh-tokoh karakter serta background yang digambar dengan tangan dan dengan sedikit teknik komputer. Animasi GIF merupakan teknik animasi yang cukup sederhana karena menggunakan prinsip animasi dasar berupa gambar-gambar yang saling dihubungkan.Storyboard adalah suatu cara untk melakukan sketsa sebuah cerita yang disusun secara berurutan untuk keperluan visualisasi sebuah animasi (Enterprise, 2016). Penggunaan animasi interaktif berupa audio, visual, dan teks diharapkan sistem pembelajaran yang interaktif (Adikara, 2016). Pembelajaran dengan media animasi interaktif bertujuan untuk membantu proses pengenalan dasar bahasa jepang sehingga membantu para pemula dalam memahami bahasa jepang secara efektif dan effisien (Hidayatun et al., 2018).

\section{METODE PENELITIAN}

Dalam penelitian ini penulis menggunakan metode pengumpulan data dan metode perangkat lunak untuk mendukung penelitian yang penulis ambil. Metode pengumpulan data yang penulis gunakan yaitu Observasi, dimana penulis melakukan pengamatan pada lembaga kursus bahasa jepang serta merujuk pada aplikasi serta website yang membahas tema yang penulis ambil. Studi Pustaka penulis mengumpulkan informasi atau referensi terkait tema yang penulis ambil yang bersumber dari buku, jurnal, maupun ebook.

Metode pengembangan perangkat lunak dalam penelitian ini penulis menggunakan metode waterfall sebagai pengembangan perangkat lunak. Metode waterfall terbagi menjadi 5 tahapan yaitu (Sukamto \& Shalahuddin, 2018) :

1) Analisis Kebutuhan Perangkat Lunak pada tahap ini penulis menganalisa permasalah dalam pembelajaran pengenalan bahasa jepang, sehingga penulis dapat menentukan aplikasi seperti apa yang akan dibuat. 2) penulis membuat rancangan storyboard sebagai bahan untuk membuat alur program serta rancangan antar muka program guna proses pengoperasian program.3) penulis melakukan pembuatan program menggunakan Adobe Flasah CS6 serta Adobe Photoshop CS6 sebagai editor pengolah gambar. 4) penulis melakukan pengujian pada program yang telah dibuat dengan menggunakan Black-Box Testing. Pengujian ini dilakukan untuk meminimalisir kesalahan yang terjadi pada program. 5) penulis melakukan pengecekan dan pemeliharaan program untuk mengetahui adanya kemungkinan perubahan pada program yang telah dibuat dikarenakan adanya kesalahan atau penambahan instrumen pada program. 


\section{HASIL DAN PEMBAHASAN}

Animasi ini ditujukan bagi para pemula yang berkeinginan untuk mempelajari dasar-dasar bahasa Jepang. Penulis membuat program animasi bagi pengguna agar pengguna dapat mudah berinteraksi serta memahami materi yang disampaikan. Dalam program animasi interaktif ini terdapat beberapa penjelasan seperti : Pengenalan Negara Jepang sebagai salah satu negara maju yang terletak di Asia. Kebudayaan jepang yang mendunia seperti manga, anime,serta cosplay

Huruf Jepang Dalam bahasa Jepang ada tiga jenis huruf yang sering digunakan yaitu, Hiragana, Katakana, dan Kanji. Selain dari ketiga huruf yang telah disebutkan, terdapat satu huruf latin atau dalam bahasa Jepang disebut roomaji. Akan tetapi penggunaan huruf ini hanya digunakan untuk kata serapan bahasa asing, atau kata yang bukan berasal dari bahasa Jepang dan tidak bisa dituliskan menggunakan huruf hiragana, katakana, maupun kanji. Huruf Hiragana digunakan dalam setiap kosakata asli dari bahasa Jepang. Huruf hiragana mempunyai 46 huruf pokok, 20 huruf turunan yang menggunakan ten-ten, dan 5 huruf yang menggunakan maru.
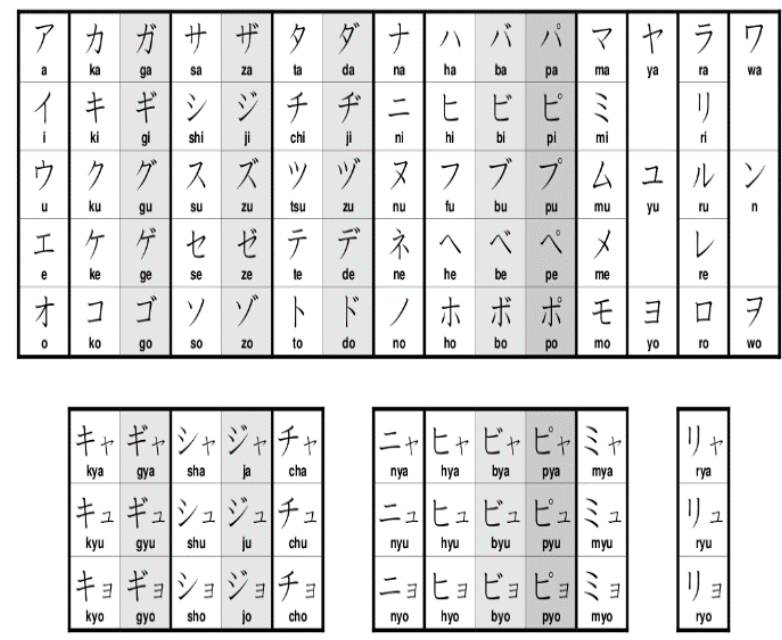

Sumber : (Data penelitian,2019)

Gambar 1. Tampilan Huruf HiraganaHuruf Katakana

Huruf Katakana digunakan antara lain untuk menulis kosakata serapan dari bahasa asing. Huruf Katakana mempunyai 46 huruf pokok, 20 huruf turunan yang menggunakan ten-ten, dan 5 huruf yang menggunakan maru.
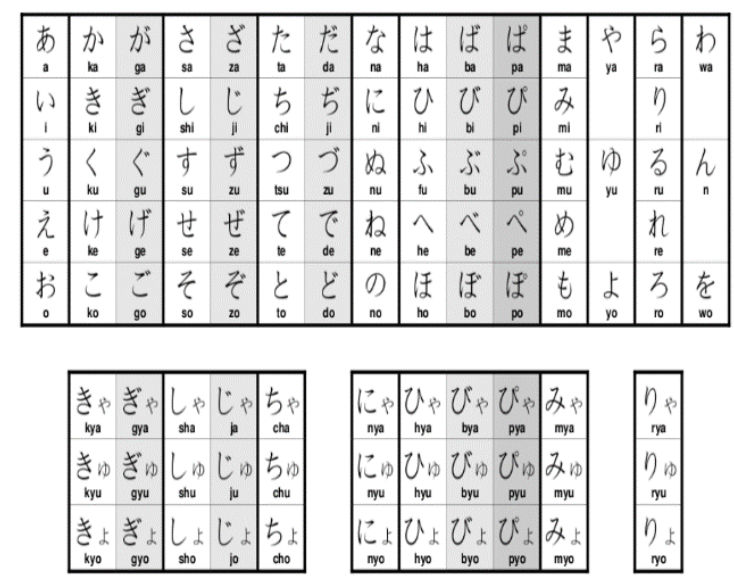

Sumber : (Data penelitian,2019)

Gambar 2. Tampilan Huruf Katakana 
Computer Science (CO-SCIENCE)

Volume 1 No. 2 Juli 2021 | E-ISSN: 2774-9711

\section{A. Perancangan Perangkat Lunak}

Rancangan Storyboard Halaman Huruf Hiragana

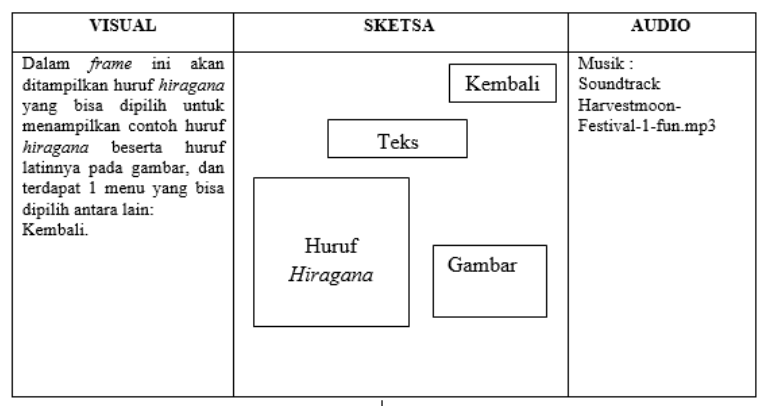

Sumber : (Data penelitian,2019)

Gambar 3. Tampilan Huruf Katakana

Rancangan Storyboard Halaman Huruf Katakana

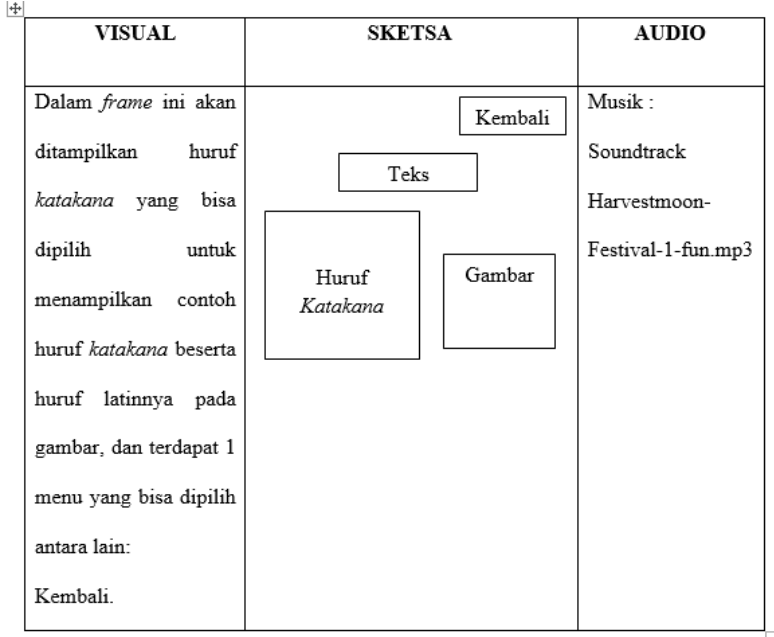

Sumber : (Data penelitian,2019)

Gambar 4. Tampilan Huruf Katakana

B. Implementasi User Interface

Tampilan Belajar Bahasa Jepang

Tampilan ini berisi 3 tombol menu yaitu tombol ke menu huruf hiragana, huruf katakana, salam, perkenalan. Dan 1 tombol navigasi untuk keluar.

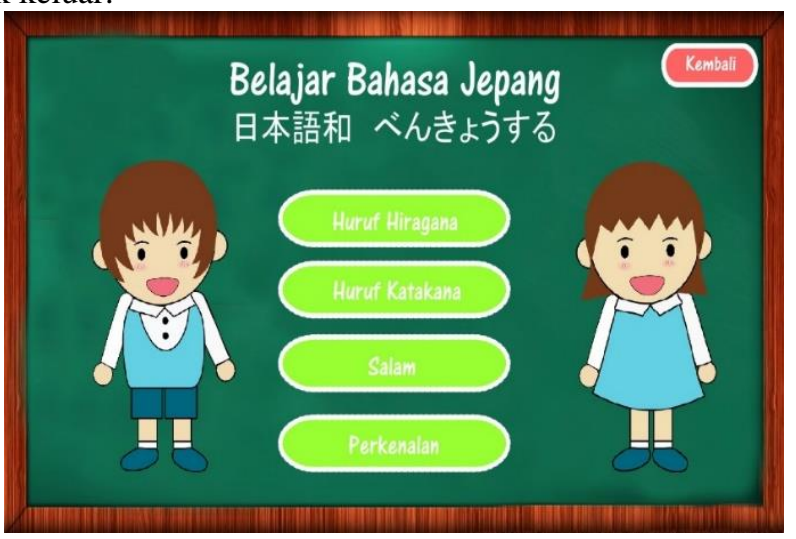

Sumber : (Data penelitian,2019)

Gambar 5. Tampilan Huruf Katakana 
Tampilan Huruf Hiragana

Tampilan ini berisi 1 tombol menu untuk menapilkan contoh huruf hiragana beserta huruf latinnya dan 1 tombol navigasi untuk kembali.

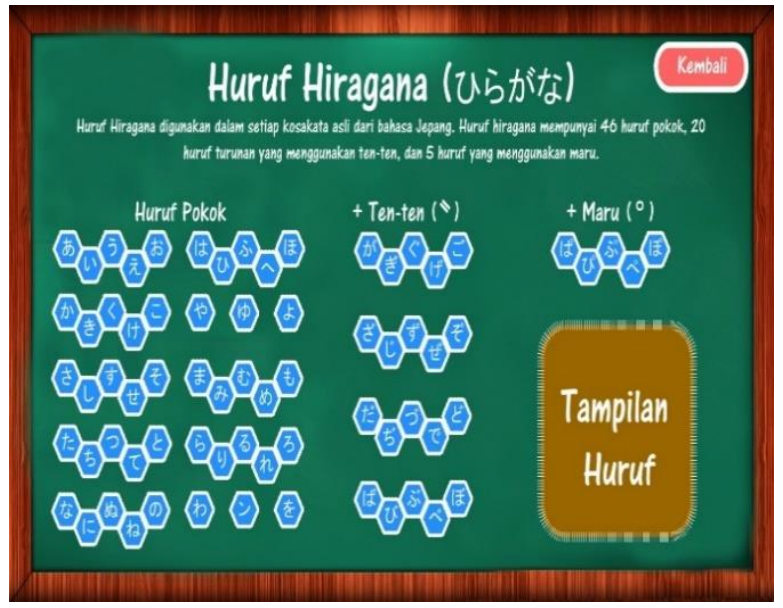

Sumber : (Data penelitian,2019)

Gambar 6.Tampilan Huruf Hiragana

Tampilan Huruf Katakana

Tampilan ini berisi 1 tombol menu untuk menapilkan contoh huruf katakana beserta huruf latinnya dan 1 tombol navigasi untuk kembali.

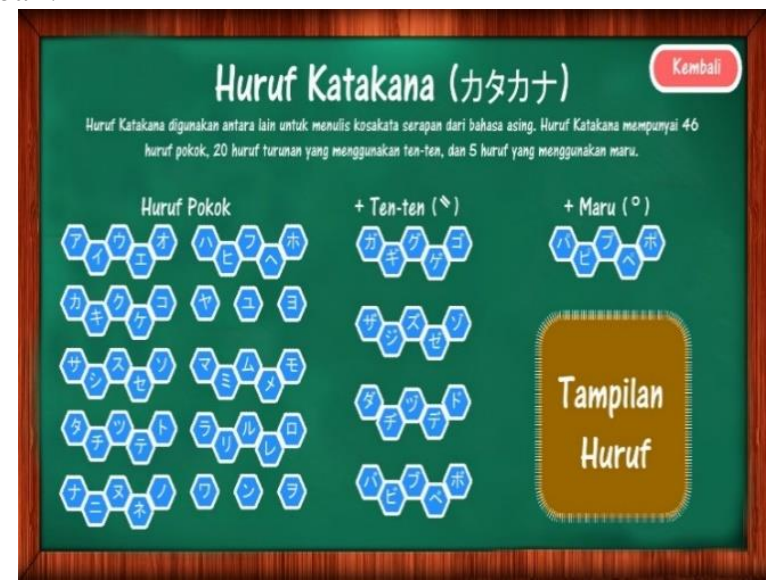

Sumber : (Data penelitian,2019)

Gambar 7. Tampilan Huruf Katakana

\section{Penerima User Terhadap Animasi}

Untuk mengetahui penilaian dari pengguna atau user terhadap animasi yang telah dibuat, penulis menggunakan metode kuesioner langsung dengan responden yang dapat mewakili pengguna. Untuk wawancara penulis mengambil narasumber sebanyak 10 (sepuluh) orang untuk mengisi kuesioner yang terdiri dari 10 pertanyaan. Dari hasil survey terhadap aplikasi pengenalan dasar bahasa Jepang ini dapat disimpulkan bahwa aplikasi ini mempunyai tampilan yang menarik dan mudah digunakan, serta dapat membantu para pengguna dalam mengenal dasar bahasa Jepang.

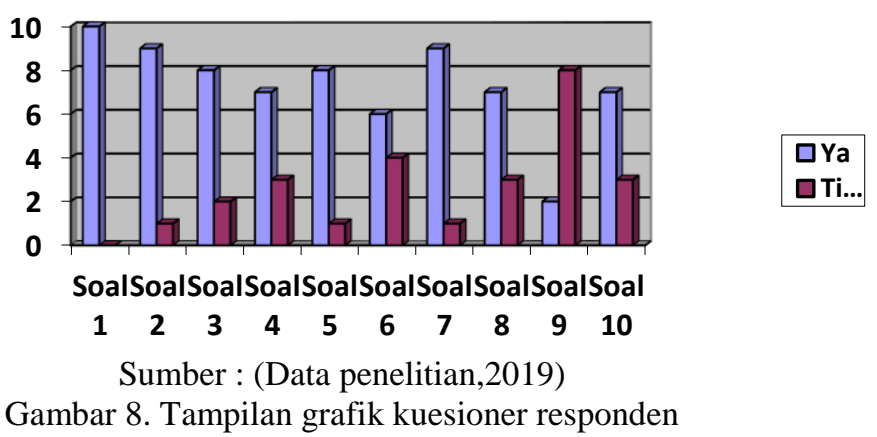




\section{KESIMPULAN}

Berdasarkan uraian yang telah penulis bahas maka dapat disimpulkan Pembuatan animasi interaktif pengenalan dasar bahasa jepang dapat dijadikan sebagai salah satu alternatif media pembelajaran bagi lembaga kursus bahasa jepang. Hal ini dapat diketahui berdasarkan dari hasil pengolahan kuesioner yang penulis berikan dimana aplikasi ini menunjukkan kemudahan penggunaan serta tampilan yang menarik menurut responden serta dianggap membantu para pengguna animasi dalam mengenal dasar bahasa jepang. Aplikasi animasi interaktif ini menyajikan unsur audio serta visualisasi yang membuat pengguna tidak merasa bosan untuk mempelajari dasar bahasa jepang. Aplikasi pengenalan dasar bahasa Jepang diharapkan dapat membantu peserta lembaga kursu dalam mempelajari dasar-dasar pengenalan bahasa Jepang. Pada aplikasi ini terdapat menu kuis yang bisa membuat para penggunanya mengetahui sejauh mana pemahaman mengenai dasar bahasa Jepang.

\section{REFERENSI}

Adikara, F. (2016). Pengembangan Fungsi Pengajuan Cuti Karyawan pada Sistem Absensi Mobile. Information System Journal, 06(01), 78-86.

Akhbar, M. N., Ridfah, A., \& Tamar, M. (2018). Pengembangan Diri Mahasiswa Universitas Hasanuddin Dalam Kaitannya Dengan Leadership Identity. Jurnal Psikologi TALENTA, 3(2), 98. https://doi.org/10.26858/talenta.v3i2.6571

Anwar, S., Schadaw, F. E., \& Althafani. (2018). Perancangan Animasi Interaktif Pengenalan Bahasa Sunda Untuk Anak-Anak Metode ADDIE. Jurnal Ilmu Pengetahuan Dan Teknologi Komputer, 3(2), 195-202.

Arnada, E. Z., \& Putra, R. W. (2018). Implementasi Multimedia Interaktif Pada PAUD Nurul Hikmah Sebagai Media Pembelajaran. Jurnal Idealis, 1(5), 393-400.

Asih, R. P., Juangsih, J., \& Rasiban, L. M. (2018). Teknik Word Flow Game Dalam Meningkatkan Kemampuan Menulis Kalimat Bahasa Jepang. JAPANEDU : Jurnal Pendidikan Dan Pengajaran Bahasa Jepang, 3(1), $38-50$.

Enterprise, J. (2016). 30 Bisnis Berbasis Ide untuk Siapapun (II). Elex Media Komputindo.

Fatihaturosyidah, F., \& Septiana, T. I. (2019). Pembelajaran Bahasa Inggris Sebagai Bahasa Asing Bagi Pembelajar Usia Dini. Aș-Șibyān: Jurnal Pendidikan Anak Usia Dini, 4(1), 63-74.

Gunawan, F., Soepriyanto, Y., \& Wedi, A. (2020). Pengembangan Multimedia Drill And Practice Meningkatkan Kecakapan Bahasa Jepang Ungkapan Sehari-Hari. JKTP: Jurnal Kajian Teknologi Pendidikan, 3(2), 187198. https://doi.org/10.17977/um038v3i22020p187

Hidayatun, N., Rosmiati, M., \& Purnama, M. R. (2018). Animasi Interaktif Berbasis Android Untuk Mengenal Huruf Hiragana Katakana. Journal Speed - Sentra Penelitian Engineering Dan Edukasi, 10(1), 1-8.

Komarudin, R., \& Noor, R. R. (2017). Analisis Perancangan Media Pembelajaran Animasi Interaktif Mengenal Bahasa Jepang. Jurnal Pilar Nusa Mandiri, 13(1), 12-20.

Rosmiati, M. (2019). Animasi Interaktif Sebagai Media Pembelajaran Bahasa Inggris Menggunakan Metode ADDIE. Paradigma - Jurnal Komputer Dan Informatika, 21(2), 261-268. https://doi.org/10.31294/p.v21i2.6019

Rostineu. (2018). 30 Hari Belajar Bahasa Jepang.

Sitepu, T., \& Rita. (2017). Bahasa Indonesia Sebagai Media Primer Komunikasi Pembelajaran. Pendidikan Bahasa Dan Sastra Indonesia, 2(1), 67-73.

Sukamto, R. A., \& Shalahuddin, M. (2018). Rekayasa Perangkat Lunak Terstruktur dan Berorientasi Objek. Informatika Bandung. 